\title{
QUEEN'S
UNIVERSITY
BELFAST
}

\section{Demand response to improved walking infrastructure: A study into the economics of walking and health behaviour change}

Longo, A., Hutchinson, W. G., Hunter, R. F., Tully, M. A., \& Kee, F. (2015). Demand response to improved walking infrastructure: A study into the economics of walking and health behaviour change. Social Science \& Medicine, 143, 107-116. https://doi.org/10.1016/j.socscimed.2015.08.033

Published in:

Social Science \& Medicine

Document Version:

Peer reviewed version

Queen's University Belfast - Research Portal:

Link to publication record in Queen's University Belfast Research Portal

Publisher rights

(C) 2015, Elsevier. Licensed under the Creative Commons Attribution-NonCommercial-NoDerivatives 4.0 International

http://creativecommons.org/licenses/by-nc-nd/4.0/ which permits distribution and reproduction for non-commercial purposes, provided the author and source are cited.

\section{General rights}

Copyright for the publications made accessible via the Queen's University Belfast Research Portal is retained by the author(s) and / or other copyright owners and it is a condition of accessing these publications that users recognise and abide by the legal requirements associated with these rights.

Take down policy

The Research Portal is Queen's institutional repository that provides access to Queen's research output. Every effort has been made to ensure that content in the Research Portal does not infringe any person's rights, or applicable UK laws. If you discover content in the Research Portal that you believe breaches copyright or violates any law, please contact openaccess@qub.ac.uk. 


\section{Demand response to improved walking infrastructure:}

\section{A study into the economics of walking and health behaviour change}

Alberto Longo, 1,3,* W. George Hutchinson, ${ }^{1,3}$ Ruth Hunter, ${ }^{2}$ Mark A Tully2,3, Frank Kee, ${ }^{2,3}$

${ }^{1}$ School of Biological Sciences, Gibson Institute, Institute for Global Food Security, Queen's University Belfast

${ }^{2}$ School of Medicine, Dentistry and Biomedical Sciences, Queen's University Belfast

3 UKCRC Centre of Excellence for Public Health (NI)

* Corresponding author: Dr. Alberto Longo, Tel. +44(0)28 9097 2063, Fax: +44(0)2890975873, e-mail: a.longo@qub.ac.uk

\section{Acknowledgements}

This study has been supported by the grant G0802045 from the National Prevention Research Initiative. The Funding Partners are (in alphabetical order): Alzheimer's Research Trust; Alzheimer's Society; Biotechnology and Biological Sciences Research Council; British Heart Foundation; Cancer Research UK; Chief Scientist Office, Scottish Government Health Directorate; Department of Health; Diabetes UK; Economic and Social Research Council; Engineering and Physical Sciences Research Council; Health and Social Care Research and Development Division of the Public Health Agency (HSC R\&D Division); Medical Research Council; The Stroke Association; Welsh Assembly Government and World Cancer Research Fund. The authors also wish to acknowledge funding from the UKCRC Centre of Excellence for Public Health Northern Ireland. 


\section{Abstract}

Demand response to improved walking infrastructure:

\title{
A study into the economics of walking and health behaviour change
}

\begin{abstract}
Walking is the most common form of moderate-intensity physical activity among adults, is widely accessible and especially appealing to obese people. Most often policy makers are interested in valuing the effect on walking of changes in some characteristics of a neighbourhood, the demand response for walking, of infrastructure changes. A positive demand response to improvements in the walking environment could help meet the public health target of 150 minutes of at least moderate-intensity physical activity per week. We model walking in an individual's local neighbourhood as a 'weak complement' to the characteristics of the neighbourhood itself. Walking is affected by neighbourhood
\end{abstract} characteristics, substitutes, and individual's characteristics, including their opportunity cost of time. Using compensating variation, we assess the economic benefits of walking and how walking behaviour is affected by improvements to the neighbourhood. Using a sample of 1,209 respondents surveyed over a 12 month period (Feb 2010-Jan 2011) in East Belfast, United Kingdom, we find that a policy that increased walkability and people's perception of access to shops and facilities would lead to an increase in walking of about 36 minutes/person/week, valued at $₫ 13.65 /$ person/week. When focusing on inactive residents, a policy that improved the walkability of the area would lead to guidelines for physical activity being reached by only $12.8 \%$ of the population who are currently inactive.

Additional interventions would therefore be needed to encourage inactive residents to achieve the recommended levels of physical activity, as it appears that interventions that 
1 improve the walkability of an area are particularly effective in increasing walking among

2 already active citizens, and, among the inactive ones, the best response is found among

3 healthier, younger and wealthier citizens.

\section{Highlights}

5 - First paper to model the demand response for walking using weak complementarity

- First paper to model effects of investment in walking infrastructure on walking

7 behaviour

8

- Maximizing walkability increases walking on average by 36 minutes/person/week

- Urban renewal programs can be designed to improve the health of inactive residents

- Through walkability upgrades guidelines for physical activity are met by $12.8 \%$ of inactive people Keywords: United Kingdom, revealed preferences, demand response, walking, weak complementarity; valuation 


\section{1. Introduction}

2 An increasing proportion of the population being overweight or obese in most Western

3 societies is leading to a significant burden on society and contributing to the rise of conditions such as diabetes, cardiovascular disease and cancer (James et al, 2004; WHO,

5 2011). Physical activity levels are on the decline in Northern Ireland, as in other countries,

6 including England, (Farrell et al, 2013, SportNI, 2010), with 60\% of the local adult population

7 not meeting the recommended levels of activity (DHSSPS, 2011). Physical inactivity, in

8 addition to unhealthy diet, has fuelled the rising level of obesity within the population, with

$959 \%$ of adults in Northern Ireland either overweight or obese (DHSSPS, 2011). Obesity has become an economic burden as well as a major health problem (Müller-Riemenschneider et al. 2007) and, as a result, governments and public health agencies are diverting considerable resources to prevent obesity and promote healthy lifestyles (Fit Futures, 2006; Butland et al., 2007; DHSSPS, 2010). The UK Department of Health recommends that adults should aim to be physically active on a daily basis and over the period of a week should aim to achieve at least 150 minutes of moderate intensity physical activity in bouts of 10 minutes or more (DoH, 2011a). Significant health consequences arise from not meeting the recommended levels of activity, including higher relative risk (adjusted for known confounders) of coronary heart disease, type 2 diabetes, breast cancer, colon cancer and all-cause mortality (Lee et al, 2012). However if the recommended guidelines for physical activity are met, then the population can expect a lower average Body Mass Index (BMI), a reduced incidence of lifestyle diseases related to obesity, such as type 2 diabetes mellitus and high blood pressure, and lower associated healthcare costs (Frank et al, 2009, Auchincloss et al, 2009, Ogilvie et al, 2007). 
1 Walking is the most common form of moderate-intensity physical activity among adults

2 (Siegel et al, 1995; Eyler et al, 2003; Ogilvie et al, 2007; Sport NI, 2010), is widely accessible

3 and especially appealing to obese people, who are less likely to perform vigorous-intensity

4 physical activity (Erlichman et al, 2002). It is an aerobic exercise that confers the diverse

5 health benefits of physical activity with few adverse effects (Morris and Hardman, 1997).

6 Several studies have confirmed that walking reduces the development of cardiovascular

7 diseases (Jones and Eaton, 1994; Albright and Thompson, 2006; Boone-Heinonen et al.,

8 2010), even though the health improvements are smaller for obese people (Boone-

9 Heinonen et al., 2010).

Many factors influence or facilitate the choice to walk for either travel or recreational purposes, including the availability of footpaths, the attractiveness of the route (e.g. interesting facades, a variety of architecture, the absence of long, blank walls), route choices for variety and safety, the number of destinations within a walkable distance (e.g. work places or nearby shops), and the opportunity cost of walking. Walking interventions include education and encouragement, as well as infrastructure investments, such as better street lighting, improved footpaths, and the creation of attractive green open spaces. Behavioural changes can arise from the increases in access, attractiveness, safety, comfort and security that these improvements offer (Krizek et al, 2009). Interventions aimed at increasing walking have been shown to be effective (Ogilvie et al, 2007), but policy makers making investment decisions aimed at improving the infrastructure for walking may wish to consider the costs and the benefits of such interventions (Dallat et al, 2014). Whilst their costs can relatively easily be quantified using market data, the monetary benefits of such interventions, in terms of increased walking, are more difficult to assess and estimate (Litman, 2003). One notable exception is the World Health 
1 Organization's Health Economic Assessment Tool (HEAT) for estimating the monetary health

2 benefits from reduced mortality from interventions aimed at increasing walking and cycling

3 (Kahlmeier, 2010; WHO, 2014). This paper aims to quantify such benefits in monetary terms

4 and to answer the following questions. What is the monetary value and the demand for

5 walking in an individual's neighbourhood? How are these monetary benefits and demand

6 affected by the characteristics of the neighbourhood, and by its improvements? What is the

7 value of the health benefits that might accrue from the additional walking associated with

8 the demand response to neighbourhood improvements? How do these benefits vary for

9 respondents with different health levels?

We address these questions by proposing an economic model of walking, based on the assumption that walking in a neighbourhood is affected by the characteristics of the neighbourhood itself, substitutes for walking in the neighbourhood and that walking is a function of the value of time.

In the next section, we review previous studies on the economics of walking. Section three describes our economic model for walking. Section four presents the case study of walking in East Belfast, Northern Ireland. The results of the econometric analysis are reported in section five, with section six presenting forecasts of demand response (resulting behaviour change) and welfare calculations. Section seven concludes with a discussion of the results and suggestions for further research.

\section{The economics of walking}

Several studies have successfully modelled the economics of walking, spanning the well developed disciplines of outdoor recreation (see Burt and Brewer, 1971, McConnell and Strand, 1981, Herriges and Kling, 1999), active transportation (see Button, 2010), and health 
1 related physical activity (Humphreys and Ruseski, 2007 and 2011). Jones and Eaton (1994),

2 investigating how walking affects the relative risk of developing coronary heart disease,

3 found that if all inactive people began walking regularly, the US would save US\$4.3bn annually. Other studies have focussed on both cycling and walking. Saelensminde (2004)

5 conducted a cost-benefit analysis of walking and cycling track networks in three Norwegian

6 cities taking into account insecurity, health effects and external costs of motorized traffic.

7 The health-economic benefits from both walking and cycling varied considerably between

8 the three cities and ranged between US\$16million and US\$258million. Wang et al (2005)

9 compared direct medical costs between active and inactive people to assess costs and benefits of building and maintaining new bike/pedestrian trails, finding a benefit cost ratio of 2.94. Sustrans (2006), in a cost-benefit analysis of three walking and cycling routes, found benefit cost ratios ranging between 14.9 and 32.5 .

The HEAT for walking and cycling (Rojas-Rueda et al, 2011; De Hartog et al, 2010; Kahlmeier, 2010; WHO, 2014) addressed the question "If $x$ people cycle or walk for y minutes on most days, what is the economic value of the health benefits that occur as a result of the reduction in mortality due to their physical activity?" (WHO, 2014, page 14). It is based on the value of a statistical life and provides a tool to estimate the health benefits in terms of mortality reduction from walking or cycling interventions. Using the HEAT method, Rabl and de Nazelle (2012) found that for a driver who switches to cycling or walking for a commute of $5 \mathrm{~km}$ (one way) 5 days/week 46 weeks/year the health benefit from the physical activity is worth about $1,200 € /$ year, even though it may be questionable whether a person would actually walk $10 \mathrm{~km} /$ day for commuting purposes.

Other studies have used the hedonic price method, focussing on "walkability" - the quality of walking conditions, including safety, comfort and convenience - and how this is affected 
1 by development density, land use mix, provision of public open space and pedestrian

2 infrastructure (Cortright, 2009; Sohn et al., 2012). Such studies have found that house

3 prices in more walkable neighbourhoods are about US\$4,000 - US\$34,000 higher than

4 houses located in areas with average levels of walkability.

5 Although the economics of walking may have been relatively overlooked by health economists, it has been extensively investigated in transportation economics and the economics of outdoor recreation. The transportation literature has most commonly used a value of time trade-off method to compare different transportation modes including walking (see Beesley, 1965; Wardman, 1998; Small and Verhoef, 2007). Walking is not a popular transportation mode, unless for very short journeys, and is often only considered in conjunction with a second transportation mode - walking and driving, walking and travelling by bus, or walking and travelling by train - as walking alone is impracticable for longer journeys (Litman, 2003).

The economic value of outdoor recreation sites, including walking facilities has been extensively studied, first using a revealed preference method, the travel cost method, (McConnell and Strand, 1981, Bockstael et al, 1987, Herriges and Kling 1999, Abidoye et al, 2012) and then using stated preference methods, such as contingent valuation (Bishop and Heberlein, 1979, Hutchinson et al 1999), contingent behaviour (Alberini and Longo, 2006) and choice experiments (Hanley et al, 1998, Adamowicz et al, 1998,). The travel cost model, originally conceived by Hotelling (1949) and developed by Clawson (1959) and Clawson and Knetsch (1976), treats the cost of travel to a site as a proxy for the value of the trip. In the United Kingdom, Christie and Matthews (2003) applied the travel cost model to assess the economic value of outdoor recreation in England and found that walkers in the English countryside spend around $£ 6.14$ billion a year, generating a profit in excess of $£ 2$ billion and 
1 supporting up to 245,000 full time jobs. This literature does not consider health benefits

2 which could have been gauged by the average distance walked and frequency of trips. The

3 contingent valuation method and choice experiments have also been extensively used in the

4 UK to assess the monetary value of hypothetical improvements to walking paths, recreation

5 infrastructure and access to the countryside (Bateman et al, 1996; Christie, 1999; Scarpa et

6 al, 2000a, 2000b; Angus et al, 2006; Morris et al, 2009). This is a well developed literature

7 which has ignored health benefits but often includes information on distance walked and

8 trip frequency.

9 In summary, previous studies have found that walking is affected by land use and built environment infrastructure, and that the walking infrastructure of neighbourhoods is reflected in real estate prices. The non-market value of walking has been studied extensively in both transportation and outdoor recreation studies, including the effect on demand of walking infrastructure (Scarpa et al, 2000a, 2000b), but provides no estimates of the health benefits. So extensive and well developed is this literature in outdoor recreation that there are many meta-analyses intended for benefit transfer purposes which investigate the stability of the relationship between site infrastructure and walking demand across large numbers of sites. For example, Matthews et al (2009) uses data for walking at 42 major recreation sites in Ireland and Scotland. Economists of outdoor recreation have also used detailed focus group discussions among walkers and other forest users as pilot studies to determine which attributes of forests users value and while recreation use is often mentioned health benefits have been largely overlooked (Chilton and Hutchinson 1999a 1999b and 1999c). In spite of a common interest in modeling walking demand, there is little meeting of minds between this area of environmental economics, where demand analysis is mostly conducted in willingness to pay space, and health economics, which is 
1 interested in the demand quantity response for walking, which is directly related to health

2 behavior change. In the next section we present a novel economic model of demand

3 quantity response to improvements in walking infrastructure in a residential

4 neighbourhood, using a revealed preference method that builds on the weak

5 complementary approach of the travel cost model. The travel cost model has been used in

6 very few studies for valuing health benefits, and never for valuing walking (Clarke, 1998;

7 2002; Jeuland et al, 2009). When discussing the application of non-market valuation

8 methods in health economics, Hanley et al (2003) mostly consider stated preferences

9 methods.

11 3. A model for the demand for walking in the neighbourhood

12 In this paper we are interested in valuing the demand for walking in the neighbourhood,

13 with neighbourhood walking defined as walking in the area of a city where a person also

14 lives. Walking in a neighbourhood is a good not traded in any market. To assess both the

15 demand response and the monetary benefits of transport walking and recreational walking

16 in the local neighbourhood, we rely on a non-market valuation technique, where the quality

17 of a neighbourhood is a non-market or public good (Freeman, 2003.) We assume that people receive private utility from walking in a residential neighbourhood. We further assume 'weak complementarity' between walking and a neighbourhood's pedestrian characteristics: as a neighbourhood becomes more walkable, walking in the neighbourhood increases (Saelens and Handy, 2008; Wilson et al, 2011). This latter assumption allows us to build a utility function that permits us to model changes in a public good - improvement in neighbourhood pedestrian characteristics - and to trace these changes to changes in 
1 consumption of a complementary private good - individual walking activity in the

2 neighbourhood. Consider an individual's utility function,

3

4

(1) $u_{i}\left(w_{i}, N_{i}, Z\right)$,

5

6 where $u_{i}$ is utility of individual $i, w_{i}$ is the number of minutes that individual $i$ walks in

7 his/her neighbourhood in a seven day period, $\boldsymbol{N}_{\boldsymbol{i}}$ is a vector of quality attributes of individual

8 i's neighbourhood, and $\mathbf{Z}$ is a vector of all other goods. Even though walking may be

9 considered a daily activity, we model the amount of walking in a neighbourhood on a

weekly basis, to accommodate for the fact that the amount of walking may vary between weekdays and weekends. Individual i's budget constraint is given by

(2) $y_{i}+a_{i}=\boldsymbol{Z}+p_{i} w_{i}$,

where $y_{i}$ is income, $a_{i}$ is individual $i$ 's wealth, and $p_{i}$ is the opportunity cost of time, expressed in terms of hourly wage, i.e. the price of walking. Maximization of utility subject to the budget constraint yields a system of Marshallian demand functions for walking in the neighbourhood,

(3) $w_{i}=w_{i}\left(\boldsymbol{N}_{i}, \boldsymbol{X}_{i}, p_{i}, a_{i}, s_{i}\right)$,

where $\boldsymbol{X}_{\boldsymbol{i}}$ is a vector of individual $i$ 's characteristics, such as gender, age, BMI, and $s_{i}$ is the season when individual $i$ is surveyed. We assume that the demand response for walking is affected by neighbourhood characteristics, hourly wage, and wealth. All else being equal, 
1 an improvement in neighbourhood walking characteristics will produce a positive demand

2 response for walking in the neighbourhood, $\frac{d w}{d N} \geq 0$; the more expensive walking in the

3 neighbourhood is, the less people walk in their neighbourhood, $\frac{d w}{d p} \leq 0$; as an individual

4 becomes wealthier, we assume that he/she walks less in his/her neighbourhood, as other

5 more expensive alternatives become available, $\frac{d w}{d a} \leq 0$. Walking in the neighbourhood is an

6 inferior good: as an individual becomes wealthier, walking in the neighbourhood should be

7 substituted by more expensive activities, such as cycling, driving, going for a walk at

8 substitutes sites, such as more pleasant and more distant area, or going to a golf course or

9 a gym.

To assess the non-market value of walking in the neighbourhood, we recall that the concept

11 of weak complementarity implies that the value of, or the willingness to pay (WTP) for a

12 public good equals the value of access to the private good (Freeman, 2003). The value of walking in a neighbourhood can then be calculated by estimating the Hicksian demand function for walking and then calculating the compensating variation under a hypothetical scenario where no pedestrian access to the neighbourhood is allowed. The compensating variation measures the amount of income paid or received to compensate for an exogenous change in the provision of a good that leaves an individual at the initial level of utility. Equation (3) is the Marshallian demand function, and not the Hicksian demand function. To use the Marshallian demand function, preferences must satisfy the weak complementarity assumption and the "Willig condition" (Willig, 1976), which requires, as described by Bockstael and McConnell (1993), that, at the equilibrium, the effect of a good's price change on the marginal price of quality equals the effect of a quality change on the quantity demanded of the good. In our case, the Willig condition requires that the change in the 
1 value of walking given a change in the opportunity cost of time equals the effect of a change

2 in the demand for walking given a change in neighbourhood characteristics. Given these

3 assumptions, we can use the demand function (3) to estimate the quantity and value effects

4 of a quality change in neighbourhood walking characteristics.

5 Equation (3) can be used to calculate two types of monetary values for walking: the access

6 value of all pedestrian use of the neighbourhood and the effect on walking value and

7 distance walked of a change in a characteristic of the neighbourhood. It is this demand

8 response or effect on distance walked which is the primary focus of this paper. The access

9 value is calculated as the area under the demand curve for walking from the current opportunity cost of time $p$ to the minimum level of the opportunity cost of time that induces zero consumption of walking, the so called 'choke price' $p$ *:

(4) $W T P($ all access $)=\int_{p_{0}}^{p *} w_{i}\left(\boldsymbol{N}_{i}, \boldsymbol{X}_{i}, p_{i}, a_{i}, s_{i}\right) d p_{i}$ $=m\left(\boldsymbol{N}_{\boldsymbol{i}}, \boldsymbol{X}_{\boldsymbol{i}}, p_{i}^{*}, a_{i}, s_{i}\right)-m\left(\boldsymbol{N}_{\boldsymbol{i}}, \boldsymbol{X}_{\boldsymbol{i}}, p_{i}, a_{i}, s_{i}\right)$,

where $m$ is the expenditure function and $p_{0}$ is the current opportunity cost of walking for individual $i$. Equation (4) is of particular interest to policy makers who want to assess the total economic value of walking in a neighbourhood. This measure is of interest when policy makers have to consider a drastic policy change that could result in a closure of an area for all walking activities, such as the complete removal of pedestrian access.

Most often policy makers are interested in valuing the effect on walking of changes in some characteristics of a neighbourhood, the demand response for walking, of infrastructure changes. To value a change in one or several characteristics of a neighbourhood, we estimate the demand curve (3) under current and changed neighbourhood characteristics, 
and then calculate the compensating variation and change in walking demand for the

2 proposed policy change. For an improvement in a neighbourhood quality to the level $N_{i}^{*}$, the demand for walking described by equation (3) shifts to the right. The improved welfare, the compensating variation, or the WTP, brought about by the policy change is the area between the two demand curves above $p_{0}$ :

(5) $W T P(\Delta$ in quality $)=\int_{p_{0}}^{p *} w_{i}^{*}\left(\boldsymbol{N}_{i}^{*}, \boldsymbol{X}_{\boldsymbol{i}}, p_{i}, a_{i}, s_{i}\right) d p_{i}-\int_{p_{0}}^{p *} w_{i}\left(\boldsymbol{N}_{\boldsymbol{i}}, \boldsymbol{X}_{\boldsymbol{i}}, p_{i}, a_{i}, s_{i}\right) d p_{i}$ 8

Equation (5) is useful when policy makers want to assess the monetary value of and the demand response to improvements that will affect walking in a neighbourhood by, for example, providing improved walking facilities, making green open spaces more attractive, or making an area safer from crime. Once welfare measures and demand response have been calculated, it is possible to estimate the health benefits associated with additional walking produced by the walking demand response to neighbourhood renewal programs offering improved walking infrastructure. From the point of view of health economics it is the demand response or behaviour change in walking which is of most interest. The welfare measures or WTP may be of primary interest to local government officials who may insist that projects of this type be seen to pass the benefit cost test before infrastructure investments are made.

\section{Data}

The area chosen in this study is the site of a proposed major urban regeneration public sector investment - the Connswater Community Greenway in East Belfast, Northern Ireland, United Kingdom - a the development of a $9 \mathrm{~km}$ linear park, including the provision of new 
1 cycle paths and walkways. The data were collected through in-person interviews over a 12

2 month period (Feb 2010-Jan 2011), using a random sample of addresses stratified by

3 electoral ward within a 1-mile radius of the Greenway for a total population of 73,378 (Tully

4 et al, 2013). Ethical approval for the study was provided by OREC, Northern Ireland,

5 (Reference, 09/NIR02/66). (See the supplementary material for the survey instrument). In

6 each household, using the last birthday rule, an adult (16 years or older) was interviewed for

7 a final sample of 1,209 respondents. To reduce sample selection bias, interviewers would

8 make at least 3 calls to each address at varying times of the day and evening, and days of

9 the week. Our analysis, after deleting 7 respondents who were unable to walk, is characterized by the following descriptive statistics: $40.6 \%$ are male, $30 \%$ own a car, $51 \%$ are employed and almost 33\% are graduates. On average, our respondents are about 50 years old, and earn a gross weekly income of $£ 465.73$ (At the time of the survey, the exchange rate was about $1 \mathrm{GBP}(f)=1.60 \mathrm{US} \$$ ). Our sample mirrors reasonably well the characteristics of the population of the area, which has a lower proportion of females than our sample. The corresponding statistics for the population of the residents in the wards we surveyed are: female 53\%; full time or part time employed 55,9\%; average age 39 years (this is computed for the whole population, whilst our sample surveyed individuals older than 16 only) (2011 Census).

The survey queried respondents about their perceptions of the characteristics of their local neighbourhood, their health status, and the amount of walking they habitually do. Respondents were asked to rate three characteristics of their neighbourhood as either 'poor', 'fair' or 'good': 1) safety of the area from crime; 2) availability of walking paths and attractive open spaces; 3 ) availability of local shops and facilities within walking distance. 
crime, as approximately $45 \%$ of respondents rate their neighbourhood to have a good level

2 of safety, $43 \%$ consider their neighbourhoods' safety to be fair and only about $11 \%$ of

3 participants deem their area 'poor' in terms of safety from crime. Our participants also consider their neighbourhood to score quite well in terms of availability of walking paths

5 and attractive open spaces, with almost $80 \%$ of respondents judging their neighbourhoods' availability of walking facilities to be either 'good' or 'fair'. Finally, most respondents (72.3\%) say that there is a good availability of local shops and facilities within walking distance. Next, we assigned each respondent to an objectively measured walkability index ranging

9 from 1 to 4 (1=Low walkability; 2=low-med; 3=med-high; 4=high). This index is calculated for the neighbourhood where respondents live, based on residential density, street sidewalk intersection density, land use mix, and retail floor area ratio following methods outlined in Leslie et al, 2007 and Frank et al, 2010. The median value for this variable is equal to 2 , suggesting that East Belfast is equally split between areas characterized by good walkability and areas with poor walkability.

To measure health outcome, we used the EQ-5D-5L standardised instrument, available at www.euroqol.org. Most respondents consider that they enjoy good health, as, on average, they report their health status to be equal to 73 , on a 1 to 100 scale, where 1 means very poor, and 100 excellent. Despite this data, our sample confirms the prevalence of obesity in Northern Ireland, as most of our respondents are either overweight (36\%) or obese (20\%), and the median (self reported) BMI is equal to 25.84 .

Respondents were instructed to consider the amount of time they spend walking to and from places such as work, shops and places of worships and for recreational purposes. They were first asked about how much time they spent walking in a typical week at this time of the year. Next, they were asked about how much of that time they spent walking in their 
1 neighbourhood. The first question on walking aims at making the respondent think about all

2 the walking he/she usually does, and at assessing any substitutes for walking in a

3 respondent's neighbourhood. The second question is the one of interest to us, as this

4 question allows us to assess the amount of walking in a person's neighbourhood. Thus over

5 a seven day period, the median respondent reports walking 150 minutes. Of these, 100

6 minutes are spent walking in his/her local neighbourhood. From these answers we notice

7 that half of our sample currently does less than the recommended amount of physical

8 activity. To account for any substitutes for walking, respondents reported the amount of

9 moderate intensity physical activity per day, which on average is about 28 minutes per

10 respondent. Descriptive statistics for our sample are reported in Table 1. 


\begin{tabular}{|c|c|c|c|c|c|c|}
\hline Variables & $\mathrm{N}$ & Mean & Std Dev & Minimum & Maximum & Median \\
\hline $\begin{array}{l}\text { Walkab (objective measure of } \\
\text { walkability: 1=Low walkability; } \\
\text { 2=low-med; 3=med-high; 4=high) }\end{array}$ & 1192 & 2.42 & 1.12 & 1 & 4 & 2 \\
\hline BMI & 1137 & 26.52 & 5.53 & 15.06 & 57.47 & 25.84 \\
\hline age & 1185 & 50.29 & 18.94 & 16 & 94 & 49 \\
\hline income & 1038 & 465.73 & 388.90 & 90 & 1500 & 340 \\
\hline health ( $1=$ very poor; $100=$ excellent) & 1198 & 73.77 & 19.65 & 3 & 100 & 80 \\
\hline $\begin{array}{l}\text { In a typical day, how many minutes } \\
\text { do you spend doing moderate- } \\
\text { intensity physical activity? }\end{array}$ & 1202 & 28.40 & 55.19 & 0 & 420 & 0 \\
\hline $\begin{array}{l}\text { G1 In a typical week at this time of } \\
\text { year how much time do you spend } \\
\text { walking? (MINUTES) }\end{array}$ & 1202 & 243.64 & 319.30 & 0 & 3300 & 150 \\
\hline $\begin{array}{l}\text { G2 And how much of that time do } \\
\text { you spend walking in your local } \\
\text { neighbourhood? (MINUTES) }\end{array}$ & 1202 & 175.35 & 247.03 & 0 & 2400 & 100 \\
\hline \multicolumn{6}{|l|}{ Dummy variables $(\mathrm{N}=1202)$} & Mean \\
\hline \multicolumn{6}{|c|}{ walkab_miss (dummy variable for missing 'walkability') } & 0.0083 \\
\hline \multicolumn{6}{|c|}{ BMI_miss (dummy variable for missing 'BMI') } & 0.0541 \\
\hline \multicolumn{6}{|c|}{ age_miss (dummy variable for missing 'age') } & 0.0141 \\
\hline \multicolumn{6}{|c|}{ income_miss (dummy variable for missing 'income') } & 0.1364 \\
\hline \multicolumn{6}{|c|}{ health_miss (dummy variable for missing 'health') } & 0.0033 \\
\hline \multicolumn{6}{|c|}{ crime_good (equals to 1 when safety of the area from crime is good) } & 0.4509 \\
\hline \multicolumn{6}{|c|}{ walk_good (equals to 1 when availability of walking paths and attractive open spaces is good) } & 0.4318 \\
\hline \multicolumn{6}{|c|}{$\begin{array}{l}\text { shop_good (equals to } 1 \text { when availability of local shops and facilities within walking distance is } \\
\text { good) }\end{array}$} & 0.7230 \\
\hline \multicolumn{6}{|c|}{ Male (equals to 1 when a respondent is male) } & 0.4060 \\
\hline \multicolumn{6}{|c|}{ Degree (equals to 1 if a respondent has at least a graduate degree) } & 0.3278 \\
\hline \multicolumn{6}{|c|}{ Couple (equals 1 if a respondent is married or living with a partner) } & 0.4991 \\
\hline \multicolumn{6}{|c|}{ Car (equals to 1 if a respondent has at least one car in the household) } & 0.2920 \\
\hline \multicolumn{6}{|c|}{ Spring (equals to 1 if a respondent was surveyed in Spring) } & 0.1963 \\
\hline \multicolumn{6}{|c|}{ Summer (equals to 1 if a respondent was surveyed in Summer) } & 0.1988 \\
\hline \multicolumn{6}{|c|}{ Autumn (equals to 1 if a respondent was surveyed in Autumn) } & 0.2471 \\
\hline \multicolumn{6}{|c|}{ Winter (equals to 1 if a respondent was surveyed in Winter) } & 0.3577 \\
\hline
\end{tabular}

\section{5. Econometric Analysis}

4 To model the demand for walking, we use a tobit model (Tobin, 1958) to account for the

5 fact that time spent walking is either positive or zero. We estimate the following regression

6 model based on equation (3): 
(6) $w_{i}=\boldsymbol{Y}_{i} \boldsymbol{\beta}_{\boldsymbol{y}}+\varepsilon_{i}$,

2

3 where $w_{i}$ is the number of minutes walked in the neighbourhood in a seven day period by

4 respondent $i ; \boldsymbol{Y}$ is a vector comprising an intercept, neighbourhood characteristics, respondent's $i$ characteristics, including a variable that captures the value of time, calculated as $15 \%$ of the net weekly income, divided by the number of minutes worked; $\boldsymbol{\beta}_{\boldsymbol{y}}$ is a vector of coefficients to be estimated; $\varepsilon_{i}$ is an error term assumed to be independently and normally distributed with mean zero and variance $\sigma^{2}$. Table 2 reports the output of three specifications for the tobit model. We favour the use of a tobit model because the data for time spent walking conform to a 'corner solution model', being either zero or positive, as indicated by Wooldridge (2002). Using ordinary least squares would result in inconsistent parameter estimates. An alternative model would be to apply a Cragg model, a two stage model where first a dichotomous choice model estimates the decision to participate in walking and then a truncated model is estimated on the assumption that when an individual decides to participate, the quantity of walking is positive. One of the difficulties in using a two-step model, like the Cragg model, would be in deciding which variables to use to explain the decision to participate. In addition, a Cragg model would underestimate the demand responsiveness, as much of this would be captured by the decision to participate.

In Table 2, Model (1), we use only an intercept, walkability (walkab), that ranges from 1 to 4 (1=Low walkability; 4=high walkability) and a dummy variable (walkab_miss) as explanatory variables. To circumvent the problem of missing values in some of our independent variables, we recode an independent variable to zero when missing and create a dummy variable, that takes on a value of one when the independent variable is missing and zero 
1 otherwise, and entering both the recoded independent variable and the indicator of a

2 missing value in the right-hand side of the equation (Longo and Alberini, 2006). Variables for

3 which we have missing observations are: walkab, BMI, age, income and health. We find that

4 walkability is positive and significant, suggesting that the more objectively 'walkable' an

5 area is, the more time people spend walking. The variable 'walkab_miss' is not statistically

6 significant, indicating that respondents for whom we have no information about the

7 walkability of their area are not different in terms of amount of walking from respondents

8 for whom we do have information on the walkability of their area. We look at the effects of

9 other variables in the next specification.

10 The second specification, Table 2, Model (2), investigates the effects on walking of

11 respondents' subjective perceptions of the walkability of the area, in addition to the objective walkability measure, by studying the effect of (a) safety of the area from crime, (b) availability of walking paths and attractive open spaces, and (c) availability of local shops and facilities within walking distance, as perceived by the respondents. The results show that walking is positively affected by the presence of shops and facilities at walking distance, whilst the safety of the area and the availability of walking paths and attractive open space, as perceived by respondents do not affect time spent walking. 
1 Table 2. Tobit model. Dependent variable is minutes walked in the neighbourhood in a

2 seven day period.

\begin{tabular}{|c|c|c|c|c|c|c|c|c|}
\hline & \multicolumn{2}{|c|}{ Model 1} & \multicolumn{2}{|c|}{ Model 2} & \multicolumn{2}{|c|}{ Model 3} & \multicolumn{2}{|c|}{ Model 4} \\
\hline & Coeff. & t-ratio & Coeff. & t-ratio & Coeff. & t-ratio & Coeff. & t-ratio \\
\hline Constant & 60.84 & 2.98 & 17.56 & 0.68 & -55.99 & -0.64 & -56.84 & -0.66 \\
\hline Crime_good & & & -23.31 & -1.26 & -19.19 & -1.05 & -14.95 & -0.82 \\
\hline Walk_good & & & 19.98 & 1.02 & 16.97 & 0.87 & 20.46 & 1.06 \\
\hline Shop_good & & & 66.81 & 3.21 & 52.40 & 2.50 & 52.80 & 2.53 \\
\hline Walkab & 32.46 & 4.28 & 31.04 & 3.96 & 28.55 & 3.61 & 22.45 & 2.78 \\
\hline Walkab_miss & 58.09 & 0.69 & 53.59 & 0.56 & 64.13 & 0.68 & 42.71 & 0.46 \\
\hline BMI & & & & & -2.84 & -1.74 & -2.70 & -1.66 \\
\hline BMI_miss & & & & & -1.32 & -0.02 & -1.85 & -0.03 \\
\hline Male & & & & & 15.07 & 0.87 & 18.86 & 1.10 \\
\hline Age & & & & & 0.11 & 0.04 & 1.77 & 0.66 \\
\hline Age_squared & & & & & -0.01 & -0.55 & -0.03 & -1.32 \\
\hline AGE_miss & & & & & -35.24 & -0.37 & -9.85 & -0.10 \\
\hline Spring & & & & & 73.49 & 3.11 & 68.28 & 2.88 \\
\hline Summer & & & & & 104.13 & 4.43 & 96.08 & 4.08 \\
\hline Autumn & & & & & 56.27 & 2.55 & 54.81 & 2.50 \\
\hline Health & & & & & 1.86 & 4.14 & 2.06 & 4.56 \\
\hline Health_miss & & & & & 105.94 & 0.67 & 107.35 & 0.68 \\
\hline Substitute & & & & & & & 0.02 & 0.41 \\
\hline Car & & & & & & & -50.17 & -2.46 \\
\hline Income & & & & & & & -0.03 & -1.65 \\
\hline Income_miss & & & & & & & -59.50 & -0.30 \\
\hline Sigma & 286.44 & 42.69 & 284.95 & 42.73 & 278.46 & 42.83 & 276.92 & 42.83 \\
\hline Observations & \multicolumn{2}{|c|}{1202} & \multicolumn{2}{|c|}{1202} & \multicolumn{2}{|c|}{1202} & \multicolumn{2}{|c|}{1202} \\
\hline Log-likelihood & \multicolumn{2}{|c|}{-7062.37} & \multicolumn{2}{|c|}{-7054.781} & \multicolumn{2}{|c|}{-7022.60} & \multicolumn{2}{|c|}{-7016.94} \\
\hline AIC & \multicolumn{2}{|c|}{11.75} & \multicolumn{2}{|c|}{11.75} & \multicolumn{2}{|c|}{11.71} & \multicolumn{2}{|c|}{11.71} \\
\hline $\mathrm{BIC}$ & \multicolumn{2}{|c|}{11.77} & \multicolumn{2}{|c|}{11.78} & \multicolumn{2}{|c|}{11.79} & \multicolumn{2}{|c|}{11.80} \\
\hline
\end{tabular}

3 
1 The third specification in Table 2, Model (3), adds respondents' socio economic

2 characteristics, in addition to the 'walkability' index of the area and respondents'

3 perceptions about the quality of their neighbourhood. We find that the higher the BMI and

4 the poorer the health, the less a respondent walks. Walking does not appear to differ with

5 age and gender. Walking is lowest in winter (reference dummy), increases in spring, peaks in

6 summer, and declines in autumn.

7 In the fourth specification, Table 2, Model 4, we add variables for respondents' income, car

8 ownership and minutes of walking in a different area to a respondent's neighbourhood,

9 calculated as the total amount of walking minus the amount of walking in a respondent's neighbourhood, which aims to capture the effect of substitute opportunities for walking.

Similarly, the variable 'car', captures both a measure of wealth, as well as a substitution possibility for walking as a mode of transport. A log-likelihood ratio test shows that model 4 outperforms model 3 at the $5 \%$ level (Chi-squared is equal to 11.32, with 4 degrees of freedom). This specification confirms the findings of previous specifications: walking increases with an increase in the objective walkability of an area, with the increased supply of shops and facilities at walking distance, with the good health of a respondent and decreases with an increase in BMI. In addition, we find that whilst walking in a neighbourhood is not affected by how much a person walks elsewhere, owning a car reduces the amount of walking. We also find a negative and significant coefficient for income, suggesting that walking in a person's neighbourhood is an inferior good: the higher the salary, the less a person walks in her/his neighbourhood. In specifications not reported here, we investigated any spatial effects by running cluster regression models (Wooldridge, 2001), using dummy variables for the wards where residents live, but found the coefficients of the cluster dummy variables to be not statistically significant. 


\section{6. Demand Response and welfare analysis for improved walking infrastructure}

3 We use the results of Model 4 to calculate the marginal effects on walking, reported in Table 3:

5

6

(7) $\frac{\partial E\left[w_{i} \mid y_{i}\right]}{\partial y_{i}}=\beta \Phi\left(\frac{y_{i}^{\prime} \beta}{\sigma}\right)$

7

Table 3. Marginal effects (minutes of walking per week)

\begin{tabular}{lll}
\hline & Marginal effect & Std. \\
\hline Shop_good & 36.48 & 14.40 \\
Walkab & 15.51 & 5.58 \\
BMI & -1.86 & 1.12 \\
Spring & 47.18 & 16.37 \\
Summer & 66.38 & 16.28 \\
Autumn & 37.87 & 15.17 \\
Health & 1.42 & 0.31 \\
Car & -34.67 & 14.08 \\
Income & -0.02 & 0.01 \\
\hline
\end{tabular}

9

Respondents rating their area as having 'good' availability of shops and facilities in their neighbourhood walk on average 36.48 minutes (std. err. 14.40) more per week compared to people who live in areas rated as having poor or fair availability of shops and facilities at walking distance. This also means that improving an area's availability of shops and facilities improves walking by more than half an hour per week. Car ownership decreases the walking in an area by 34.7 minutes (std. err.14.08) per week, suggesting that policies that increase the cost of car ownership or car usage may have an important effect on the amount of

17 physical activity that people do. Interventions that improve the objective walkability of an area lead to an increase in walking of about a quarter of an hour per week. The table also 
1 shows strong seasonality in walking patterns: in summer people walk about one hour and 6

2 minutes more than in winter, a result that is consistent with previous literature (Tucker and

3 Gilliland, 2007).

$4 \quad$ We use model (4) and equations (4) and (5) to calculate the demand response and monetary

5 value of improved walking infrastructure in the neighbourhood. Using equation (6),

6 considering that the 'choke price', $\mathrm{p}^{*}$, is the price that sets the demand for neighbourhood

7 walking to zero, equation (4) becomes:

8

9

(8) $W T P($ access $)=\int_{p_{0}}^{p *} \boldsymbol{Y}_{i} \boldsymbol{\beta}_{\boldsymbol{y}} d p_{i}=-\frac{\widehat{w}^{2}}{\beta_{p}}$,

where $\widehat{w}$ is the predicted number of minutes walked per week from equation (4) and model

(3). Using equation (8), the access value to walking in the neighbourhood is equal to $£ 33.27$

(std. err.20.21, calculated with the delta method) per week. This is the monetary value that, on average, a person living in East Belfast values the right of access to walking in the neighbourhood.

The access value is, however, of limited interest, as it is unlikely that a neighbourhood becomes unavailable for walking. More interesting is an assessment of the monetary value and especially the supply response to interventions aimed at improving the walkability of the area. To value a change in one or several characteristics of a neighbourhood, we use model (4) and equations (5) and (8) under current and changed neighbourhood characteristics:

(9) $\operatorname{WTP}(\Delta$ in quality $)=\int_{p_{0}}^{p *} \boldsymbol{Y}_{\boldsymbol{i}}^{*} \boldsymbol{\beta}_{\boldsymbol{y}} d p_{i}-\int_{p_{0}}^{p *} \boldsymbol{Y}_{\boldsymbol{i}} \boldsymbol{\beta}_{\boldsymbol{y}} d p_{i}=-\frac{\widehat{w} *^{2}}{\beta_{p}}+\frac{\widehat{w}^{2}}{\beta_{p}}$, 
2 Where $\boldsymbol{Y}_{i}^{*}$ is the demand for walking under improved neighbourhood characteristics, and $\widehat{w}^{*}$

3 is the predicted number of minutes spent walking - the demand response for walking - in a seven day period estimated from model (3) and (6) under improved neighbourhood

5 characteristics. For example, a policy that improved East Belfast walkability from the current levels to the 'high' level of walkability throughout the district and that also improved people's perceptions of their areas from the current levels to 'good' levels in terms of availability of local shops and facilities within walking distance would result in an increase of walking for the average respondent of 36.18 minutes (std. err. 9.93) per week. Such a policy is valued at $£ 13.65$ (std. err. 9.49) per week. Table 4 reports a set of demand responses for walking and related monetary values for selected scenarios.

Table 4. Increased minutes of walking per week and monetary value of (WTP) in GBP (f) for selected scenarios. Standard errors calculated with the Delta Method.

\begin{tabular}{lcc}
\hline Scenario & $\begin{array}{c}\text { WTP } \\
\text { (std. err.) }\end{array}$ & $\begin{array}{c}\text { Increased } \\
\text { minutes of } \\
\text { walking (std. } \\
\text { err.) }\end{array}$ \\
\hline $\begin{array}{l}\text { Improving East Belfast to high walkability; good availability of local shops } \\
\text { and facilities within walking distance; all other variables at their mean }\end{array}$ & 13.65 & 36.18 \\
value & $(9.49)$ & $(9.93)$ \\
Improving East Belfast's availability of local shops and facilities within & 3.62 & 10.24 \\
walking distance to 'good'; all other variables been at the average value & $(2.63)$ & $(4.09)$ \\
Improving East Belfast's walkability to 'high'; all other variables been at & 9.30 & 25.31 \\
the average value & $(6.98)$ & $(9.38)$ \\
Respondent interviewed in spring with BMI=23, gross weekly income=500, & 18.13 & 39.96 \\
health status=85, no car for improving East Belfast to 'high' walkability and & $(13.00)$ & $(10.89)$ \\
'high' availability of local shops and facilities within walking distance & & 34.94 \\
Respondent interviewed in spring, BMI=32, gross weekly income=500, & 12.12 & $(8.74)$ \\
health status=55, no car; improving East Belfast to 'high' walkability and & $(8.74)$ & \\
'high' availability of local shops and facilities within walking distance & & \\
\hline
\end{tabular}


1 We notice the differences between normal weight and obese respondents, with the latter

2 having a considerably lower value for improvements in their neighbourhood and also a

3 lower increase in expected walking. For example, a policy that improves the walkability to

4 'high' and also improves people's appreciation of the availability of shops and facilities at

5 walking distance to 'good', leads to an increase of almost 40 minutes per week of walking

6 for a respondent with a health status of 85 and BMI of 23, and of only 35 minutes for a less

7 healthy respondent with a health status of 55 and a BMI of 32. Although obese people walk

8 at a slower speed (Browning and Kram, 2005), they would accumulate a similar amount of

9 energy expenditure from 35 minutes of walking - 170 kcals if walking at 3.0 Metabolic

10 Equivalent of Task (METs) - compared to the normal weight individual walking for 40

11 minutes - 164 kcals if walking at 3.5 METs - assuming they were both of similar height (1.7m

12 in this example) (Bushman, 2011).

\section{Discussion and conclusion}

Walking in the area where a person lives is a widely accessible form of moderate-intensity physical activity, suitable for overweight and obese people, as well as for older people with limited mobility or limited transport opportunities, who are less likely to perform vigorousintensity physical activity. Walking has been found to improve human health by reducing the development of cardiovascular diseases and cancer. Given its importance, it is surprising that there has been little health economic research into modelling the demand response which is linked to behaviour change. In this paper we have introduced a novel revealed preference model of the demand response for walking and the enhanced value of neighbourhood walking which results from improvements in neighbourhood walkability and 
1 walking infrastructure. The model assumes that walking in a neighbourhood depends on the

2 characteristics of the neighbourhood, as well as residents' characteristics. We have found

3 that walking in the area where a person lives is an "inferior" good: as an individual becomes

4 wealthier, walking in the neighbourhood will be substituted with more expensive activities,

5 such as cycling, driving, walking in a different area outside the neighbourhood, or going to

6 the golf course and the gym. To our knowledge, this is the first time that such a model has

7 been proposed for estimating the demand response, the potential health benefits and

8 consumer's value of walking. We have applied the model to walking in East Belfast,

9 Northern Ireland, UK, and find that our empirical data supports our theoretical model: minutes walked are negatively affected by the value of time and by a person's wealth. We

further find that people living in more walkable areas and in areas which have a good availability of local shops and facilities within walking distance, tend to report walking more than other people.

Considering the monetary value of walking, a public programme that would enhance to a 'high' level the walkability of all of East Belfast and improve to 'good' all resident's perception of the availability of local shops and facilities within walking distance is valued at $£ 13.65$ (std. err. 9.49) per person per week. Assuming that estimated levels would correspond to actual behaviours, the corresponding increase in minutes walked per week from such a policy should result in 36.18 (std. err. 9.93) extra minutes walked per person on average. These results show that a policy that would produce an increase of about one quarter of the recommended amount of moderate-intensity physical activity has an average annual value per resident of about $f 710$. When we apply the WHO's HEAT methodology (WHO, 2014) to our data, using a value of a statistical life for the UK of $£ 3.2 \mathrm{M}$, and a mortality rate of 432.1 deaths per 100,000 people per year, we find that the same policy 
1 would be worth about $£ 34$ per resident per year. This is a much lower estimate than the one

2 arising from our model, suggesting that the WHO's HEAT methodology underestimates the

3 total value of walking, as it only focuses on the health benefits of walking from mortality risk

4 reduction.

5 One may wonder whether individuals who like walking may decide to live in more walkable

6 areas. To address this point, we investigate any difference in walking outside an individual's

7 neighbourhood. Using a t-test, we find no difference ( $p$-value $=0.93279)$ in mean values for

8 walking outside an individual's neighbourhood for people living in high walkability areas

9 (walkab $=3$ or 4 ) and for people living in low walkability areas (walkab $=1$ or 2 ). From this result, it appears that people walk more in more walkable areas because they live in those areas, and not because they walk more in general. Future longitudinal studies should cast more light on this issue.

From a policy perspective, it may be interesting to investigate the effects on inactive residents, to gauge the impact on the numbers becoming active and reaching the recommended guidelines of 150 minutes per week of moderate-intensity physical activity. When we focus our attention on inactive participants, respondents who currently do not engage in at least 30 minutes of moderate-intensity physical activity per day, and walk less than 150 minutes per week, we find that this group of 567 respondents (about $44 \%$ of our survey sample) only walks a total of 105 minutes per week on average. These are respondents with an average $\mathrm{BMI}$ of 25.40 , are on average 53 years old, predominantly female (62\%), with a self-reported health value of 68.5 , and a weekly income of $£ 373$. Our demand response model shows that if the government implemented a public program to maximize the walkability of East Belfast and to improve residents' perceptions of the attractiveness of the area, then these inactive respondents would, on average, increase 
1 their amount of walking by 38.49 minutes (std. err. 10.25) per week. Such a program would

2 therefore increase, on average, the total amount of moderate-intensity physical activity for

3 this group of inactive residents to about 142 minutes per week, an increase of about 35\%, an important amount, though still short of the recommended 150 minutes per week. Put

5 another way, this policy would help an additional $12.8 \%$ of the inactive sample ( 73 people) -

6 who do not currently meet the recommended guidelines for physical activity - achieve the

7 recommended target of 150 minutes per week of physical activity. Interestingly, when we

8 look at the average characteristics of these 73 respondents, we find that this is a relatively

9 young group, about 47 years old, with a large proportion of men, $44 \%$, with a BMI of 24.7 , a self-reported health status value of 75 , and a weekly income of $£ 421$, a healthier (and wealthier) group compared to those not achieving the recommended targets for physical activity after the implementation of the walkability improvements.

Additional interventions would therefore be needed to encourage inactive residents to achieve the recommended levels of physical activity, as it appears that interventions that improve the walkability of an area are particularly effective in increasing walking among already active citizens, and, among the inactive ones, the best response is found among those healthier, younger and wealthier citizens. Sattelmair et al. (2011) have shown that compared to taking no physical activity, people who are physically active at half the recommended level (75 minutes per week), are at a 14\% lower risk of coronary heart disease. Our findings of a possible increase of nearly 30 minutes on average per week of activity from infrastructure and walkability changes to the neighbourhood may therefore be associated with widespread health benefits. Compared with completely inactive adults, Wen et al (2011) have demonstrated that those who undertake low levels of activity (90 minutes per week), had a $14 \%$ reduced risk of all-cause mortality, and had a 3 year longer 
1 life expectancy. After that, every additional 15 minutes of activity (half the level we have

2 demonstrated) further reduced all-cause mortality by $4 \%$ and all-cancer mortality by $1 \%$.

3 These benefits were applicable to all age groups and both sexes. Considering the results of

4 these studies in conjunction with our findings, we conclude that a policy that improved the

5 walkability in East Belfast to a high level and also improved to 'good' residents' perceptions

6 of the availability of local shops and facilities within walking distance, would contribute to

7 an increase in moderate-intensity physical activity of about 36 minutes on average per

8 week, which could result in a reduced all-cause mortality by about $8 \%$ and all-cancer

9 mortality by about $2 \%$.

10 Capewell and Graham (2010) and the recent guidelines from the National Institute for

11 Health and Care Excellence (NICE, 2010) have highlighted how population level measures are generally more effective at narrowing inequalities than interventions targeted at individuals, which may widen inequalities. Our findings demonstrated that for poorer respondents it is relatively less costly to do physical activity in their neighbourhood than elsewhere. However, we also found that an intervention that improves the walkability and the subjective perceptions of the walkable environment where people live is more effective in increasing physical activity levels of already healthy (and wealthier) people. It is therefore vital that we are never seduced by our assumptions (about whole population approaches) and that all public health programmes are evaluated appropriately to mitigate any potential for intervention generated inequalities (Frohlich and Potvin, 2008). One must also be mindful that there are likely to be synergies between physical and social infrastructure (Diez Roux and Mair, 2010) and that changes in social norms (around walking) may also change individual's utility functions (Prior et al 2014) and that even this might have a differential effect across socioeconomic groups. 
1 Our conclusions must be guarded, as the analysis is obviously subject to assumptions

2 concerning the relationship between revealed and actual behaviour which can be tested

3 more robustly by natural field observations after an urban regeneration has taken place. In

4 addition, our WTP perspective might be thought of as providing a lower bound to the

5 monetary benefits to the public sector of such walking infrastructure improvements. It does

6 not include indirect benefits that might arise from improved business and tourism in areas

7 with improved infrastructure, and reduced pollution.

8 Information on the monetary health benefits of walking may also be useful to policymakers

9 since there has been considerable debate about the use of incentives for behavioural change. We found that individuals with a greater BMI have lower values for walking in their neighbourhood and, when compared to people with lower BMI, are likely to change their physical activity levels less under the various improvement scenarios. Therefore, it could be that differential incentives may be required to improve physical activity levels. Larger incentives may be needed to modify the behaviour of individuals with higher BMI values, a suggestion that accords with previous research (Ogilvie, 2007), but which needs to be empirically tested.

Our research finds that in Belfast, at least, people do not seem to be walking for health reasons alone, they walk "opportunistically", that is, to reach a destination to undertake regular daily activities such as shopping, eating out, going to places of worship etc., while other physical activities seem to be associated with more moderate-intensity and vigorousintensity activities such as going to the gym, playing sports etc. This is entirely borne out by the findings of our recent qualitative work with stakeholders of the Connswater Community Greenway (Prior et al, 2014). From these findings we derive two messages for policy makers: 1) walkability is increased by the placing of typical urban structures and functions 
1 such as shops, restaurants, libraries and playgrounds within walking distance of as many

2 people as possible, and 2) ordinary walking is a healthy activity and this includes all walking-

3 not just walking for long periods, at a very fast pace or hiking.

4 As a methodological contribution to the literature, this paper has used a novel revealed

5 preferences method to model the demand and value of neighbourhood walking in the event

6 of interventions to improve pedestrian infrastructure in the district. Further research should

7 explore the use of stated preferences, also in conjunction with revealed preferences, to

8 investigate the benefits of walking and other forms of physical activity. Stated preferences

9 may be used to further validate the findings from revealed preferences, and/or to explore

10 scenarios that cannot be studied with revealed preferences alone. 


\section{References}

Abidoye, B.O., Herriges, J.A., \& Tobias, J.L. (2012). Controlling for Observed and Unobserved Site Characteristics in RUM Models of Recreation Demand. American Journal of Agricultural Economics, 94(5), 1070-1093.

Adamowicz, V., Boxall, P., Williams, M., \& Louviere, J.J. (1998). Stated preference approaches for measuring passive use values: choice experiments and contingent valuation. American Journal of Agricultural Economics, 80, 64-75.

Alberini, A., \& Longo, A. (2006). Combining The Travel Cost And Contingent Behavior Methods To Value Cultural Heritage Sites In A Transition Economy: Evidence From Armenia. Journal of Cultural Economics, 30(4), 287-304.

Albright, C., \& Thompson, D.L. (2006). The effectiveness of walking in preventing cardiovascular disease in women: A review of the current literature. Journal of Women's Health, 15, 271-280.

Angus, A., Brawn, M., Morris, J., Parsons, D., \& Stacey, K. (2006). The social and economic benefits of public rights of way-quantifying value for money. Final Report, Defra Project EPES 0506/07. Department for Environment, Food and Rural Affairs: London.

Auchincloss, A.H., Diez Roux, A.V., Mujahid, M.S, Shen, M., Bertoni,A.G., \& Carnethon, M.R. (2009). Neighborhood Resources for Physical Activity and Healthy Foods and Incidence of Type 2 Diabetes Mellitus. The Multi-Ethnic Study of Atherosclerosis. Archives of Internal Medicine, 169(18), 1698-1704.

Bateman, I.J., Diamond, E., Langford, I.H., \& Jones, A. (1996). Household willingness to pay and farmers' willingness to accept compensation for establishing a recreational woodland. Journal of Environmental Planning and Management, 39, 21-43. 
Beesley, M.E. (1965). The value of time spent in travelling: some new evidence. Economica, 32, 174- 185.

Bishop, R.C., \& Heberlein, T.A. (1979). Measuring Values of Extra-Market Goods: Are Indirect Measures Biased? Amer. J. Agr. Econ, 69, 26-30.

Bockstael, N., Strand I.E., \& Hanemann W.M. (1987). Time and the recreation demand model. American Journal of Agricultural Economics, 69, 293-302.

Bockstael, N., \& McConnell T. (1993). Public goods as characteristics of non-market commodities. The Economic Journal, 103, 1244-1257.

Boone-Heinonen, J., Evenson K.R., Taber D.R., \& Gordon-Larsen P. (2009). Walking for prevention of cardiovascular disease in men and women: a systematic review of observational studies. Obesity Reviews, 10, 204-217.

Browning, R., \& Kram R. (2005) "Energetic Cost and Preferred Walking Speed in Obese vs. Normal Weight Women" Obesity Research Vol 13, Issue 5, pp 891-99.

Burt, O.R., \& Brewer, D. (1971). Estimation of Net Social Benefits from Outdoor Recreation. Econometrica, 39, 812-27.

Bushman, B. (2011). ACSM's Complete Guide to Fitness \& Health. American College of Sports Medicine; Campaign, IL.

Butland, B., Jebb, S., Kopelman, P., McPherson, K., Thomas, S., Mardell, J., \& Parry, V. (2007). Foresight. Tackling obesities: future choices. Project report. Foresight. Tackling obesities: future choices. Project report.

Button, K.J. (2010). Transport Economic $3^{\text {rd }}$ Edition. Edward Elgar Publishing Company, Aldershot, England.

Capewell, S., Graham, H. (2010). Will Cardiovascular Disease Prevention Widen Health Inequalities? PLoS Med,7(8), e1000320. 
NISRA (2011). Census 2011. Northern Ireland Statistics and Research Agency.

Chilton, S.M. \& Hutchinson, W.G. (1999a). The role of focus groups in the CV process. Journal of Economic Psychology, 20, 465-483

Chilton, S.M. \& Hutchinson, W.G. (1999b). Focus groups and the CV process: A reply Journal of Economic Psychology, 20, 495-498

Chilton, S.M. \& Hutchinson, W.G. (1999c) Exploring divergence between respondent and researcher definition of the good in CV studies. Journal of Agricultural Economics, 50(1), $1-16$

Christie, M. (1999) Designing strategic recreation policy using contingent valuation. Journal of Environmental Planning and Management 1999;42; 547-564.

Christie, M. \& Matthews, J. (2003). The economic and social value of walking in England. Report for the Ramblers' Association: London.

Clarke, P.M. (1998). Cost-benefit analysis and mammographic screening: a travel cost approach. Journal of Health Economics, ,17, 767-787.

Clarke, P.M. (2002). Testing the convergent validity of the contingent valuation and travel cost methods in valuing the benefits of health care. Health Economics, 11, 117-127.

Clawson, M. (1959). Methods of measuring demand for and the value of outdoor recreation. U.S. Resources for the Future: Washington, DC;

Clawson, M., \& Knetsch, J.L. (1976). The economics of outdoor recreation. Johns Hopkins Press: Baltimore.

Cortright, J. (2009). Walking the walk: How walkability raises home values in U.S. cities, available at http://www.citeulike.org/group/11305/article/5541951 (accessed 20/5/2015). 
Dallat, M.A.T., Soerjomataram, I., Hunter, R.F., Tully, M.A., Cairns, K.J., Kee, F. (2014). Urban greenways have the potential to increase physical activity levels cost-effectively. Eur J Public Health, 24(2), 190-5.

DHSSPS (2006). Fit futures. Investing for health; Department of Health, Social Services and Public Safety Northern Ireland.

DHSSPS (2010). Obesity prevention framework 2011-2012. Department of Health, Social Services and Public Safety Northern Ireland; Health Development Policy Branch: Northern Ireland.

DHSSPS (2011). Health survey Northern Ireland: First results from 2010/11 survey. Department of Health, Social Services and Public Safety: Northern Ireland; 2011.

De Hartog, J.J., Boogaard, H., Nijland, H., Hoek, G. (2010). Do the health benefits of cycling outweigh the risks? Environ Health Perspect, 118, 1109-16.

Diez Roux, A.V., \& Mair, C. (2010). Neighborhoods and health. Ann. N.Y. Acad. Sci. 1186; 125-145.

DoH (2011). Start active, stay active. A report on physical activity for health from the four home counties' Chief Medical Officers. UK Department of Health: London.

Erlichman, J., Kerbey, A.L., \& James, W.P. (2002). Physical activity and its impact on health outcomes. Paper 2: prevention of unhealthy weight gain and obesity by physical activity: an analysis of the evidence. Obesity Reviews,3, 273-287.

Eyler, A.A., Brownson, R.C., Bacak, S.J., \& Housemann, R.A. (2003). The epidemiology of walking for physical activity in the United States. Medicine \& Science in Sports \& Exercise,35, 1529-1536.

Farrell, L., Hollingsworth, B., Propper, C., \& Shields, M.A. (2013). The socioeconomic gradient in physical inactivity in England. CMPO Working Paper Series No. 13/311. 
2 Frank, L., Kerr, J., Saelens, B., Sallis, J., Glanz, K., \& Chapman, J. (2009). Food outlet visits, physical activity and body weight: variations by gender and race-ethnicity. British Journal of Sports Medicine, 43(2), 124-131.

Frank, L. D., Sallis, J. F., Saelens, B. E., Leary, L., Cain, K., Conway, T. L., \& Hess, P. M. (2010). The development of a walkability index: application to the Neighborhood Quality of Life Study. British journal of sports medicine, 44(13), 924-933.

Freeman, A.M. (2003). The measurement of environmental and resource values: Theory and methods. Resources for the Future: Washington DC.

Frohlich, K. L., \& Potvin, L. (2008). Transcending the known in public health practice: the inequality paradox: the population approach and vulnerable populations. American journal of public health, 98(2), 216-221.

Hanley, N., Wright, R. E., \& Adamowicz, V. (1998). Using choice experiments to value the environment. Environmental and resource economics, 11(3-4), 413-428.

Hanley, N., Ryan, M., \& Wright, R. (2003). Estimating the monetary value of health care: lessons from environmental economics. Health economics, 12(1), 3-16.

Herriges, J.A., Kling, C.L. (Eds.). (1999). Valuing recreation and the environment: revealed preference methods in theory and practice. Edward Elgar, Aldershot, UK.

Hotelling, H. (1949). Letter of June 18, 1947, to Newton B. Drury. Included in the report The Economics of Public Recreation: An Economic Study of the Monetary Evaluation of Recreation in the National Parks, 1947-15.

Humphreys, B. R., \& Ruseski, J. E. (2007). Participation in physical activity and government spending on parks and recreation. Contemporary Economic Policy, 25(4), 538-552. 
Humphreys, B. R., \& Ruseski, J. E. (2011). An economic analysis of participation and time spent in physical activity. The BE Journal of Economic Analysis \& Policy, 11(1), 1-36.

Hutchinson, W. G., Scarpa, R., Chilton, S. M., \& McCallion, T. (2001). Parametric and NonParametric Estimates of Willingness to Pay for Forest Recreation in Northern Ireland: A Discrete Choice Contingent Valuation Study with Follow-Ups. Journal of Agricultural Economics, 52(1), 104-122.

James, W. P. T., Jackson-Leach, R., Mhurchu, C. N., Kalamara, E., Shayeghi, M., Rigby, N. J., ... \& Rodgers, A. (2004). Overweight and obesity (high body mass index). Comparative quantification of health risks: global and regional burden of disease attribution to selected major risk factors, 1, 497-596.

Jeuland, M., Lucas, M., Clemens, J., \& Whittington, D. (2010). Estimating the private benefits of vaccination against cholera in Beira, Mozambique: A travel cost approach. Journal of Development Economics, 91(2), 310-322.

Jones, T. F., \& Eaton, C. B. (1994). Cost-benefit analysis of walking to prevent coronary heart disease. Archives of family medicine, 3(8), 703-710.

Kahlmeier, S., Racioppi, F., Cavill, N., Rutter, H., \& Oja, P. (2010). "Health in All Policies" in Practice: Guidance and Tools to Quantifying the Health Effects of Cycling and Walking. Journal of physical activity \& health, 7(1), S120.

Krizek, K. J., Handy, S. L., \& Forsyth, A. (2009). Explaining changes in walking and bicycling behavior: challenges for transportation research. Environment and planning. B, Planning \& design, 36(4), 725-740.

Lee, I. M., Shiroma, E. J., Lobelo, F., Puska, P., Blair, S. N., Katzmarzyk, P. T., \& Lancet Physical Activity Series Working Group. (2012). Effect of physical inactivity on major non- 
communicable diseases worldwide: an analysis of burden of disease and life expectancy. The lancet, 380(9838), 219-229.

Leslie, E., Coffee, N., Frank, L., Owen, N., Bauman, A., \& Hugo, G. (2007). Walkability of local communities: using geographic information systems to objectively assess relevant environmental attributes. Health \& place, 13(1), 111-122.

Litman, T. A. (2003). Economic value of walkability. Transportation Research Record: Journal of the Transportation Research Board, 1828(1), 3-11.

Longo, A., \& Alberini, A. (2006). What are the effects of contamination risks on commercial and industrial properties? Evidence from Baltimore, Maryland. Journal of Environmental Planning and Management, 49(5), 713-737.

Matthews, D. I., Hutchinson, W. G., \& Scarpa, R. (2009). Testing the stability of the benefit transfer function for discrete choice contingent valuation data. Journal of Forest Economics, 15(1), 131-146.

McConnell, K. E., \& Strand, I. (1981). Measuring the cost of time in recreation demand analysis: an application to sportfishing. American Journal of Agricultural Economics, 63(1), 153-156.

Morris J.N., \& Hardman, A.E. (1997). Walking to health. Sports Med, 23, 306-32.

Morris, J., Colombo, S., Angus, A., Stacey, K., Parsons, D., Brawn, M., \& Hanley, N. (2009). The value of public rights of way: A choice experiment in Bedfordshire, England. Landscape and Urban Planning, 93(1), 83-91.

Müller-Riemenschneider, F., Reinhold, T., Berghöfer, A., \& Willich, S. N. (2008). Healtheconomic burden of obesity in Europe. European journal of epidemiology, 23(8), 499509. 
1 National Institute for Clinical Excellence (NICE). (2010). Prevention of cardiovascular disease at population level. NICE Public Health Guidance 25.

Ogilvie, D., Foster, C. E., Rothnie, H., Cavill, N., Hamilton, V., Fitzsimons, C. F., ... \& Scottish Physical Activity Research Collaboration. (2007). Interventions to promote walking: systematic review. BMJ, 334, 1204-1213.

Prior, L., Scott, D., Hunter, R., Donnelly, M., Tully, M. A., Cupples, M. E., \& Kee, F. (2014). Exploring lay views on physical activity and their implications for public health policy. A case study from East Belfast. Social Science \& Medicine, 114, 73-80.

Rabl, A., \& De Nazelle, A. (2012). Benefits of shift from car to active transport. Transport policy, 19(1), 121-131.

Rojas-Rueda, D., de Nazelle, A., Tainio, M., \& Nieuwenhuijsen, M. J. (2011). The health risks and benefits of cycling in urban environments compared with car use: health impact assessment study. BMJ, 343, d4521.

Sattelmair, J., Pertman, J., Ding, E. L., Kohl, H. W., Haskell, W., \& Lee, I. M. (2011). Dose response between physical activity and risk of coronary heart disease a metaanalysis. Circulation, 124(7), 789-795.

Saelens, B. E., \& Handy, S. L. (2008). Built environment correlates of walking: a review. Medicine and science in sports and exercise, 40(7 Suppl), S550-S566.

Sælensminde, K. (2004). Cost-benefit analyses of walking and cycling track networks taking into account insecurity, health effects and external costs of motorized traffic. Transportation Research Part A: Policy and Practice, 38(8), 593-606. 
1 Scarpa, R., Chilton, S. M., Hutchinson, W. G., \& Buongiorno, J. (2000a). Valuing the recreational benefits from the creation of nature reserves in Irish forests. Ecological Economics, 33(2), 237-250.

Scarpa, R., Hutchinson, W. G., Chilton, S. M., \& Buongiorno, J. (2000b). Importance of forest attributes in the willingness to pay for recreation: a contingent valuation study of Irish forests. Forest Policy and Economics, 1(3), 315-329.

Siegel, P. Z., Brackbill, R. M., \& Heath, G. W. (1995). The epidemiology of walking for exercise: implications for promoting activity among sedentary groups. American journal of public health, 85(5), 706-710.

Small, K. A., \& Verhoef, E. T. (2007). The economics of urban transportation. Routledge.

Sohn, D. W., Moudon, A. V., \& Lee, J. (2012). The economic value of walkable neighborhoods. Urban Design International, 17(2), 115-128.

Sport NI. (2010). The Northern Ireland Sport and \& Physical Activity Survey 2010 (SAPAS).

Sustrans (2006). Economic appraisal of local walking and cycling routes.

Tobin, J. (1958). Estimation of Relationships for Limited Dependent Variables, Econometrica, 26, 24-36.

Tucker, P., \& Gilliland, J. (2007). The effect of season and weather on physical activity: a systematic review. Public health, 121(12), 909-922.

Tully, M. A., Hunter, R. F., McAneney, H., Cupples, M. E., Donnelly, M., Ellis, G., ... \& Kee, F. (2013). Physical activity and the rejuvenation of Connswater (PARC study): protocol for a natural experiment investigating the impact of urban regeneration on public health. BMC public health, 13(1), 774.

Wardman, M. (1998). The value of travel time: a review of British evidence. Journal of Transport Economics and Policy, 285-316. 
1 Wang, G., Macera, C. A., Scudder-Soucie, B., Schmid, T., Pratt, M., Buchner, D., \& Heath, G. (2004). Cost analysis of the built environment: the case of bike and pedestrian trials in Lincoln, Neb. American Journal of Public Health, 94(4), 549-553.

Wen, C. P., Wai, J. P. M., Tsai, M. K., Yang, Y. C., Cheng, T. Y. D., Lee, M. C., ... \& Wu, X. (2011). Minimum amount of physical activity for reduced mortality and extended life expectancy: a prospective cohort study. The Lancet, 378(9798), 1244-1253.

WHO. (2000). Obesity: Prevention and managing the global epidemic: Report of a WHO consultation. WHO technical report series, 894.

WHO. (2011). Obesity and overweight. Fact sheet No. 311. Updated March 2011. World Health Organisation.

WHO. (2014). Health economic assessment tools (HEAT) for walking and cycling: Methods and User Guides, 2014. World Health Organization Regional Office for Europe, Copenhagen.

Willig, R. D. (1978). Incremental consumer's surplus and hedonic price adjustment. Journal of Economic Theory, 17(2), 227-253.

Wilson, L. A. M., Giles-Corti, B., Burton, N. W., Giskes, K., Haynes, M., \& Turrell, G. (2011). The association between objectively measured neighborhood features and walking in middle-aged adults. American Journal of Health Promotion, 25(4), e12-e21.

Wooldridge, J.M. (2001). Econometric Analysis of Cross Section and Panel Data. The MIT Press, Cambridge, MA. 